\title{
Dewetting of Polymer Films Controlled by Protein Adsorption
}

\author{
Natalia Janiszewska, Joanna Raczkowska, Andrzej Budkowski,* Katarzyna Gajos, Yurij Stetsyshyn, \\ Maciej Michalik, and Kamil Awsiuk*
}

Cite This: Langmuir 2020, 36, 11817-11828

Read Online

ABSTRACT: The stability of the film poly(n-butyl methacrylate) (PnBMA) with different tacticities, prepared on silicon oxide and exposed to aqueous phosphate-buffered saline with different concentrations of bovine serum albumin $\left(C_{\mathrm{BSA}}\right.$ between 0 and $\left.4.5 \mathrm{mg} / \mathrm{mL}\right)$, was examined at temperatures close to the physiological limit (between 4 and $37^{\circ} \mathrm{C}$ ) with optical microscopy, contact angle measurements, atomic force microscopy, and time-of-flight secondary ion mass spectrometry. For PBS solutions with $C_{\mathrm{BSA}}=0$, the stability of atactic PnBMA and dewetting of isotactic PnBMA was observed, caused by the interplay between the stabilizing long-range dispersion forces and the destabilizing short-range polar
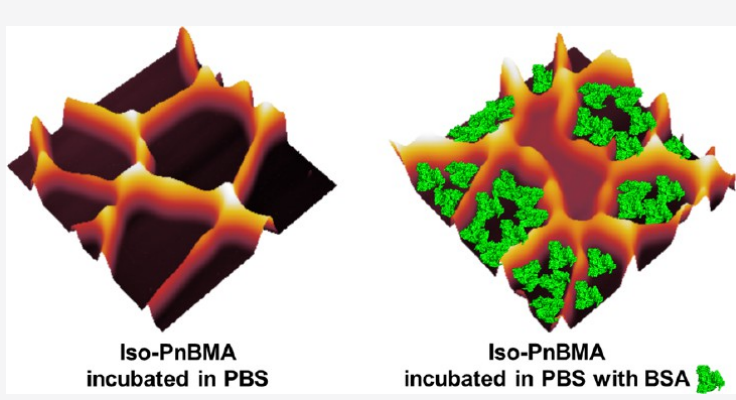
interactions. Analogous considerations of excess free energy cannot explain the retardation of dewetting observed for isotactic PnBMA in PBS solutions with higher $C_{\mathrm{BSA}}$. Instead, formation of a BSA overlayer, adsorbed preferentially but not exclusively to uncovered $\mathrm{SiO}_{x}$ regions, is evidenced and postulated to hinder polymer dewetting. Polymer dewetting and protein patterning are obtained in one step, suggesting a simple approach to fabricate biomaterials with micropatterned proteins.

\section{INTRODUCTION}

Dewetting is a commonly observed process that occurs when a continuous thin polymer film, which is not in a thermodynamically stable state, breaks up due to interfacial instabilities, initially forming holes that subsequently evolve into droplets. ${ }^{1}$ The stability of a polymer film on a given substrate is a crucial issue for its potential applications in a large variety of fields, ranging from plastic electronics, through coating industry, up to biomedical devices. ${ }^{2}$ In a majority of applications, a homogeneous film is required. Therefore, inhibition of polymer dewetting has motivated numerous studies, which reached this goal with strategies relying on surface or polymer film modification or addition of additives to the polymer (see the review by Xue and $\mathrm{Han}^{3}$ ). This work examines a novel strategy to hinder polymer dewetting based on additive (protein) addition to the phase (liquid) surrounding both the substrate and the polymer.

The dewetting process would allow us to obtain polymer structures with a predefined statistical size and spatial distribution, avoiding complicated and expensive lithographic-based methods. ${ }^{2}$ Therefore, a lot of theoretical and experimental research has been focused on dewetting., ${ }^{1,12}$ Materials organized with dewetting of surface nanotopographic patterns with a chemical contrast have been applied in biomedical fields: ${ }^{2-4}$ for instance, surface postmodification with adsorbing proteins leads to protein microarrays ${ }^{13}$ and possible subsequent cell application results in cell positioning. ${ }^{14}$ This study shows that instead of a multistep procedure, a one-step polymer dewetting procedure accompanied by protein adsorption can be used to fabricate biomaterial surfaces with micropatterned proteins.

The most extensively studied dewetting processes are driven by thermal instabilities caused by the long-range dispersion forces $^{4,15-20}$ and induced by solvents due to the short-range polar interactions. ${ }^{21-23}$ However, recently, also nonsolvent dewetting, observed for polymer films exposed to nonsolvents (or its vapors), such as water, have attracted much attention. ${ }^{24-26}$ Research on nonsolvent dewetting is extremely important for environmental fields, as polymer films can be destabilized due to humidity, and for biomedical applications, with polymer films exposed to an aqueous environment. This work explores the nonsolvent dewetting of a polymer film immersed in aqueous phosphate-buffered saline (PBS) solutions, relevant for biomedical research, also with a dissolved protein. Prior to polymer dewetting analysis, surface tension data are determined for this liquid.

Polymer films examined here are composed of poly ( $n$-butyl methacrylate) (PnBMA). PnBMA coatings are cytocompatible and therefore have potential biomedical applications. ${ }^{27}$ In addition, PnBMA is a unique polymer with the glass transition temperature $T_{\mathrm{g}}$ located in the range of physiological temper-

Received: June 10, 2020

Revised: August 6, 2020

Published: September 14, 2020 
atures. $^{27}$ Hence, protein adsorption and orientation can be temperature-controlled on PnBMA coatings through a transition from the glassy to the rubbery polymer state, changing polymer nanotopography and elasticity, with negligible changes in electrostatic, dispersion, and polar protein-polymer interactions. ${ }^{28}$ This study is an extension of our previous works on PnBMA-grafted brushes ${ }^{29,30}$ and explores the films of PnBMA with different tacticities, isotactic and atactic. In isotactic PnBMA, the substituent groups on the successive asymmetric carbons are projected on the same side of the polymer chain. In turn, in atactic PnBMA, the substituents of the successive asymmetric carbons are projected randomly on both sides of the plane in the polymer chain.

Isotactic polymers have a lower $T_{\mathrm{g}}$ compared to the atactic form, and therefore, their chains have greater mobility compared to the atactic ones. Also, different tactic versions of the same polymers were reported to have different wettabilities caused by different extents of functional groups segregated at their surface. ${ }^{50}$

We performed the complex characterization of isotactic and atactic PnBMA layers cast on silicon oxide. Optical microscopy, atomic force microscopy (AFM), time-of-flight secondary ion mass spectrometry (ToF-SIMS), and contact angle measurements (CA) were applied to reveal the stability of atactic PnBMA and the dewetting of isotactic PnBMA when immersed in PBS solutions at temperatures close to the physiological limit (between 4 and $37{ }^{\circ} \mathrm{C}$ ). Analogous experiments performed for isotactic PnBMA films immersed in PBS solutions with different concentrations of bovine serum albumin (BSA) showed retardation of dewetting for the solutions with higher $C_{\mathrm{BSA}}$. This is related to BSA adsorption to various regions of the dewetted surface, with spatial correlation between the protein and the dewetted polymer evidenced by ToF-SIMS: preferential adsorption on uncovered $\mathrm{SiO}_{x}$ regions enables protein micropatterning. In addition, increased protein surface density on elevated polymer regions such as rims points to nanotopography effects in protein adsorption. ${ }^{29}$

\section{EXPERIMENTAL SECTION}

2.1. Materials. The polymers used in this work were isotactic $(\mathrm{Mn}$ $=66 \times 10^{3}, \mathrm{PDI}=1.6$, Iso $\left.>94 \%\right)$ and atactic $\left(\mathrm{Mn}=50 \times 10^{3}, \mathrm{PDI}=\right.$ 1.09) poly ( $n$-butyl methacrylate) (PnBMA) purchased from Polymer Source Inc. (Dorval (Montreal) Quebec H9P $2 \times 8$ Canada). Bovine serum albumin (BSA; Cohn Fraction V) was obtained from Acros Organics (Thermo Fisher Scientific; Geel, Belgium). Silicon wafer (orientation: $<100>$, RMS roughness $<0.2 \mathrm{~nm}$ ) used as a substrate was purchased from Si-Mat (Kaufering, Germany).

2.2. Sample Preparation. Isotactic and atactic PnBMA films were spin-cast with analytical-grade chlorobenzene (coating speed $\omega$ $=1.5-2.2 \mathrm{krpm}$, solution concentration $\left.C_{\mathrm{P}}=10 \mathrm{mg} / \mathrm{mL}\right)$. Then, the samples were incubated in $50 \mathrm{mM}$ phosphate buffer (PBS, pH 7.4) or protein solution for $30 \mathrm{~min}$ at temperatures equal to 4,21 , and $37^{\circ} \mathrm{C}$. Concentrations of BSA in PBS solution, $C_{\mathrm{BSA}}$, were equal to 0.02, 0.1, $0.5,1$, and $4.5 \mathrm{mg} / \mathrm{mL}$ (measured with NanoDrop One, Thermo Scientific). After incubation, the samples were washed with a buffer and distilled water and dried under a $\mathrm{N}_{2}$ flow.

2.3. Water Contact Angle Measurements and Surface Energy Measurements. The wettability of the polymer films, determined as the water contact angle value, was measured using the sessile drop technique using a Kruss EasyDrop (DSA15) instrument with a Peltier temperature-controlled chamber. The measurements were carried out at temperatures ranging from 7 to $36{ }^{\circ} \mathrm{C}$ to determine the thermal response of the PnBMA films. The temperature was measured using a thermocouple in contact with the sample surface. Contact angles were expressed as the average of 10 measurements at different spots.

Static contact angles were measured for four different reference liquids: water, glycerol, formamide, and diiodomethane. The experiments were performed using the sessile drop technique using a Kruss EasyDrop (DSA15) instrument at room temperature. Contact angles were determined as the average of 10 measurements taken at different spots on the same sample surface. Then, the Owens-Wendt-Kaelble analytical approach was applied to calculate the surface free energy. ${ }^{30}$

2.4. Optical Microscopy. The evolution of the PnBMA thin films was examined using an Olympus IX51 microscope. Images were recorded using an XC30 digital camera (Olympus). The maximum resolution of images captured using this camera is $2080 \times 1544 \mathrm{px}$. All images were recorded using cellSens Dimension (Olympus) software with a 20x (Universal Plan Fluorite, magnification of 200) lens.

Optical images were analyzed using an integral geometry approach extended using the procedures described in our earlier papers. ${ }^{31-33}$ In brief, each gray scale image represents an array of pixels set to various local levels i $(x, y)$, characteristic of the surface features and correlated with a local value of height. Each pixel can be changed into white or black when its local value is, respectively, higher $\mathrm{q}_{\mathrm{i}}(\mathrm{x}, \mathrm{y})>\mathrm{q}^{\prime}$ or lower $\mathrm{q}_{\mathrm{i}}(\mathrm{x}, \mathrm{y})<\mathrm{q}^{\prime}$ than the specific threshold value $\mathrm{q}^{\prime}$. The $\mathrm{q}^{\prime}$ value is determined using the rigorously established procedures. ${ }^{31,33}$ As a result, a binary (black-and-white) image is created, and surface features can be fully characterized by three morphological (Minkowski) measures, reflecting area fraction (coverage) $\mathrm{F}$, boundary length (lateral shape) $\mathrm{U}$, and the Euler characteristic (connectivity) $\chi_{\mathrm{E}}$ of the white regions. For each image, the Minkowski measures were computed (normalized by the analyzed area) using the software developed in our laboratory. ${ }^{32}$ Their average values $(\langle\mathrm{F}\rangle$, $\langle\mathrm{U}\rangle$, and $\left.\left\langle\chi_{\mathrm{E}}\right\rangle\right)$, obtained from the analysis of several (at least five) images recorded at various spots, were used to describe and compare the surface features.

2.5. AFM Surface Examination. AFM topographic images of the PnBMA film surfaces after incubation in a buffer or protein solution were obtained using an Agilent 5500 atomic force microscope (AFM) working in a noncontact mode. AFM silicon cantilevers (PPP-FMR, Nanosensors) with a force constant of $\sim 2 \mathrm{~N} / \mathrm{m}$, a resonant frequency of $\sim 80 \mathrm{kHz}$, and tips with a standard beam shape and small radius $(<7$ $\mathrm{nm}$ ) were used. AFM micrographs were analyzed with Pico Image software.

2.6. Ellipsometry Measurements. A Sentech SE800 (SEN$\mathrm{TECH}$ Instruments $\mathrm{GmBH}$ ) spectroscopic ellipsometer working at a wavelength range of $320-700 \mathrm{~nm}$ and at a fixed angle of incidence equal to $70^{\circ}$ was used to estimate the thickness of the polymer layer. The results were analyzed with SpectraRay 3 software assuming the Cauchy dispersion formula and a two-layer model consisting of a silicon substrate and a polymer overlayer.

2.7. Time-of-Flight Secondary lon Mass Spectrometry (ToFSIMS) Surface Examination. The PnBMA surfaces were analyzed prior to and after BSA adsorption with a TOF.SIMS 5 (ION-TOF $\mathrm{GmbH}$ ) instrument using a $30 \mathrm{keV}$ bismuth liquid metal ion gun and $\mathrm{Bi}_{3}$ clusters. The surface spectra were recorded with a high mass resolution $m / \Delta m>8400$ at $\mathrm{C}_{4} \mathrm{H}_{5}{ }^{+}(m / z=53)$ and $\mathrm{C}_{4}{ }^{-}(\mathrm{m} / z=48)$ peaks for positive and negative spectra, respectively. To collect ToFSIMS images, the imaging mode was used with a worse mass resolution but better spatial resolution. To ensure a static mode condition, the dose density deposited on the surface was lower than $10^{12}$ ions $/ \mathrm{cm}^{2}$ for all samples. Positive and negative ion ToF-SIMS mass spectra were acquired from at least four different nonoverlapping $200 \mu \mathrm{m} \times 200 \mu \mathrm{m}$ spots, whereas images were recorded from $100 \mu \mathrm{m}$ $\times 100 \mu \mathrm{m}$ spots.

\section{RESULTS AND DISCUSSION}

3.1. Surface Tension, Its Dispersive and Polar Components. This study examines the stability of polymer (PnBMA) layers deposited on the silicon oxide surface and immersed in liquids, such as water, PBS, and PBS solutions of BSA. The total excess intermolecular interaction free energy 
$\Delta G$ of the above defined system is analyzed in Sections 3.2 and 3.3. For the purpose of $\Delta G$ analysis, the values of surface tension $\gamma$ and its dispersive $\left(\gamma^{\mathrm{D}}\right)$ and polar $\left(\gamma^{\mathrm{P}}\right)$ components, corresponding to surfaces of the phases that meet at the threephase contact line, are estimated first in this section.

Surface energy values $\left(\gamma, \gamma^{\mathrm{D}}\right.$, and $\left.\gamma^{\mathrm{P}}\right)$ of the silicon oxide substrate and PnBMA (both isotactic and atactic) coatings were determined using the contact angles measured for two different reference liquids (formamide and diiodomethane) and analyzed using the Owens-Wendt-Kaelble analytical approach (Table 1$).^{30}$

Table 1. Surface Tension and its Polar and Dispersive Components of the Silicon Oxide Substrate, both Iso- and at-PnBMA, As Well as Used Liquids (Water and PBS)

\begin{tabular}{clccc} 
phase & & $\gamma^{\mathrm{D}}[\mathrm{mN} / \mathrm{m}]$ & $\gamma^{\mathrm{P}}[\mathrm{mN} / \mathrm{m}]$ & $\gamma[\mathrm{mN} / \mathrm{m}]$ \\
$(1)$ & $\mathrm{SiO}_{x}$ substrate & $36.2(0.3)$ & $13.2(0.3)$ & $49.4(0.6)$ \\
$(2)$ & iso-PnBMA & $30.3(1.6)$ & $\mathbf{1 . 2}(\mathbf{0 . 4})$ & $31.5(2.0)$ \\
$(2)$ & at-PnBMA & $34.1(1.1)$ & $1.6(\mathbf{0 . 3})$ & $35.7(1.4)$ \\
$(3)$ & water & $25.0(1.0)$ & $47.8(1.0)$ & 72.8 \\
$(3)$ & PBS & $28.1(1.1)$ & $41.4(1.1)$ & 69.5 \\
\hline
\end{tabular}

To determine the polar and dispersive components of water and PBS surface energy (Table 1), we measured the contact angles of these liquids placed on four different substrates (polystyrene, poly(methyl methacrylate), at-PnBMA, and silicon oxide substrate) with defined polar and dispersive components of the surface energy.

The collected data were analyzed using the Owens-WendtKaelble analytical approach (Figure S1) with total surface energy values of 72.8 and $69.5 \mathrm{~mJ} / \mathrm{m}^{2},{ }^{34}$ taken for water and PBS, respectively. Surface tension modification of PBS with respect to that of water, with an increase expected for aqueous electrolyte solutions, ${ }^{35}$ is usually small and not resolved for 1 M PBS and biological systems. ${ }^{36}$ However, at millimolar salt concentrations corresponding to diluted PBS, the surface tension $\gamma$ exhibits a small but distinctive reduction, ascribed to bulk ion-induced water-water correlations ${ }^{37}$ competing with the electrostatic, dispersion, and hydration forces repelling ions from an air interface. ${ }^{35}$ The values of dispersive and polar components $\left(\gamma_{\text {PBS }}^{\mathrm{D}}=28.1(1.1) \mathrm{mN} / \mathrm{m}, \gamma_{\text {PBS }}^{\mathrm{P}}=41.4(1.1)\right.$ $\mathrm{mN} / \mathrm{m}$ ) of surface tension, determined with the OwensWendt-Kaelble method for the used $50 \mathrm{mM}$ PBS dilution, differ from those of water $\left(\gamma_{\text {water }}^{\mathrm{D}}=25.0(1.0) \mathrm{mN} / \mathrm{m}, \gamma^{\mathrm{P}}{ }_{\text {water }}=\right.$ $47.8(1.0) \mathrm{mN} / \mathrm{m})$ and indicate a complex interplay of different interfacial forces at millimolar salt concentrations.

To estimate the dispersive and polar part of surface tension of the BSA solution (Table 2), the contact angles of BSA solutions with concentrations $C_{\mathrm{BSA}}$ equal to $4.5,0.1$, and 0.02 $\mathrm{mg} / \mathrm{mL}$ deposited on polystyrene, poly(methyl methacrylate),

Table 2. Total Surface Tension and its Dispersive and Polar Components of BSA Solutions in PBS

$\begin{array}{cccc} & \begin{array}{c}\text { dispersive part } \\ {[\mathrm{mN} / \mathrm{m}]}\end{array} & \begin{array}{c}\text { polar part } \gamma^{\mathrm{P}} \\ {[\mathrm{mN} / \mathrm{m}]}\end{array} & \begin{array}{c}\text { total surface }^{38} \\ \text { tension }^{38}[\mathrm{mN} / \mathrm{m}]\end{array} \\ \begin{array}{c}C_{\mathrm{BSA}}=4.5 \\ \mathrm{mg} / \mathrm{mL}\end{array} & 19.9(1.1) & 39.1(1.1) & \sim 59 \\ \begin{array}{c}C_{\mathrm{BSA}}=0.1 \\ \mathrm{mg} / \mathrm{mL}\end{array} & 23.7(1.0) & 42.3(1.0) & \sim 66 \\ \begin{array}{c}C_{\mathrm{BSA}}=0.02 \\ \mathrm{mg} / \mathrm{mL}\end{array} & 29.9(1.5) & 41.1(1.5) & \sim 71\end{array}$

at-PnBMA, and silicon oxide substrate were measured (see Figure S1). As an additional constraint, the value of the total surface tension of albumin solutions in PBS varying in concentration was taken as reported by B.C. Tripp et al. ${ }^{38}$

Compared to PBS, the addition of the BSA protein to the PBS (50 mM) aqueous solution reduces the surface tension $\gamma$. This effect seems to be accompanied by the change in dispersive rather than the polar surface tension component. Both $\gamma$ and $\gamma^{\mathrm{D}}$ values decrease monotonically with protein concentration to reach $\gamma \sim 59$ and $\gamma^{\mathrm{D}} \sim 20 \mathrm{mN} / \mathrm{m}$ (with $\gamma^{\mathrm{P}} \sim$ $39 \mathrm{mN} / \mathrm{m}$ ) at $C_{\mathrm{BSA}}=4.5 \mathrm{mg} / \mathrm{mL}$. The surface activity of BSA is related to its affinity for the amphiphilic air/aqueous phase interface, driven by hydrophobic BSA surface regions, whereas polar BSA domains stay in contact with the aqueous phase. ${ }^{38,39}$ Surface tension decreases from the pure PBS dilution value only when a significant protein amount is adsorbed at the air interface with at least half monolayer surface coverage. ${ }^{38}$

3.2. Stability of PnBMA Films in the Aqueous PBS Solution. To examine the potential of PnBMA with different tacticities for biomedical applications at temperatures close to the physiological limit, atactic and isotactic PnBMA thin films were incubated in an aqueous solution of PBS at three temperatures, 4,21 , and $37{ }^{\circ} \mathrm{C}$. The representative images of both incubated layers, recorded using optical microscopy, are presented in Figure 1.

For at-PnBMA (Figure $1(\mathrm{a}-\mathrm{c})$ ), the polymer film remains stable and continuous for all analyzed temperatures. In contrast, iso-PnBMA (Figure $1(\mathrm{~d}-\mathrm{f})$ ) films are structured, and patterns characteristic of a dewetting process are observed. Moreover, also for thicker films (Figure S2), the at-PnBMA layer remains stable, whereas the iso-PnBMA layer dewets. However, the exact shape of the formed structures depends strongly not only on film thickness but also on the temperature of incubation. The iso-PnBMA films are metastable and exhibit classical heterogeneous hole nucleation. This process is slowed down for thicker films for all temperatures (Figure S2). The changes from small individual holes at $4{ }^{\circ} \mathrm{C}$ through coalesced and large holes arranged into polygonal patterns at $21{ }^{\circ} \mathrm{C}$ to the dropletlike structures at $37^{\circ} \mathrm{C}$ are observed (Figure 1). These structures resemble different stages of the thermally induced dewetting process, that is, formation and growth of holes at early stages, their coalescence into polygonal patterns with continuous rims, typical for an intermediate stage, and decay of rims into spherical droplets, characteristic of the late stage of dewetting. ${ }^{10,40,41}$

The observed temperature dependence of the dewetting process occurring for iso-PnBMA films (Figure 1d-f) can be related to the different viscosities of polymer films that control the dewetting velocity. ${ }^{42}$ Temperature-induced viscosity changes for polymer films should be similar to those determined for the bulk polymer. ${ }^{43,44}$ For PnBMA, they are described by the relaxation time following the VogelFulcher-Tammann relation above the polymer glass transition temperature $T_{\mathrm{g}}, \tau(T) \sim \exp \left(10 /\left(T-T_{\mathrm{VFT}}\right)\right),{ }^{45}$ with $T_{\mathrm{VFT}}$ observed roughly $50 \mathrm{~K}$ below $T_{\mathrm{g}}{ }^{46}$ Thus, temperature difference $\left(T-T_{\mathrm{g}}+50 \mathrm{~K}\right)$ should govern the polymer chain mobility in dewetting experiments performed at various temperatures $T$ (Figure $1 \mathrm{~d}-\mathrm{f}$ ). Polymer chain mobility is "frozen" below $T_{\mathrm{g}}$ and is very low just above $T_{\mathrm{g}}$ so that the temperature at which dewetting becomes detectable is somewhat higher (even $\sim 20 \mathrm{deg}$ ) than the effective $T_{\mathrm{g}}$ of the polymer film. ${ }^{47}$ Here, the observed different behaviors of PnBMA films with different polymer tacticities, with dewetted 

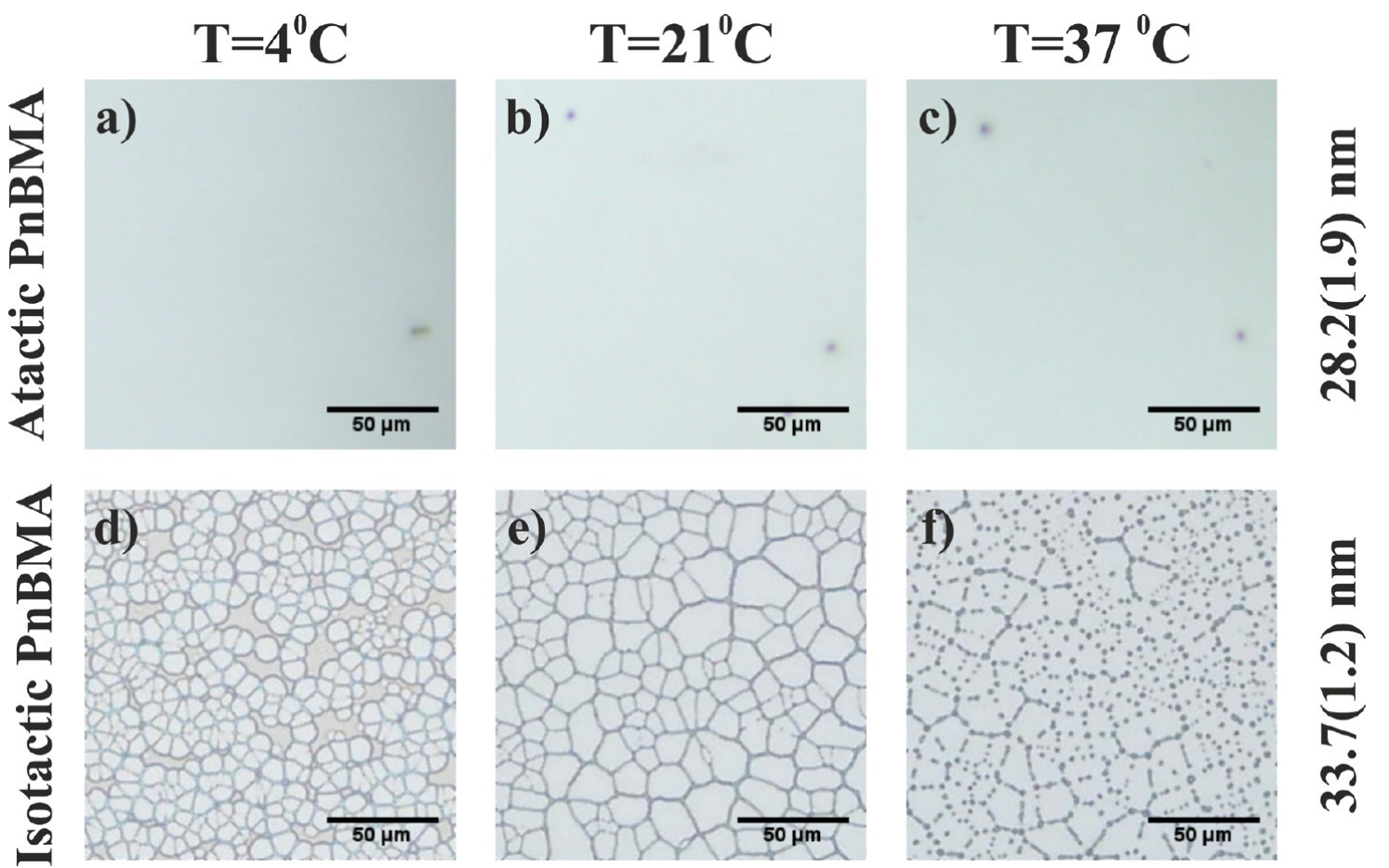

Figure 1. Optical images of $(\mathrm{a}-\mathrm{c})$ atactic and $(\mathrm{d}-\mathrm{f})$ isotactic PnBMA layers after incubation in PBS at 4,21 , and $37^{\circ} \mathrm{C}$ for 30 min. The polymer layers were prepared with comparable thicknesses of $(a-c) 28.2(1.9) \mathrm{nm}$ and $(\mathrm{d}-\mathrm{f}) 33.7(1.2) \mathrm{nm}$.

iso-PnBMA films (Figure $1 \mathrm{~d}-\mathrm{f}$ ) but stable at-PnBMA films (Figure $1 \mathrm{a}-\mathrm{c}$ ), can be related to the different glass points of these polymers, with $T_{\mathrm{g}}=29$ and $-20{ }^{\circ} \mathrm{C}$ specified by the producer for bulk polymers, at- and iso-PnBMA, respectively.

The glass transition of a polymer film can differ from that of the bulk and depends on film thickness. ${ }^{47,48}$ The glass point determined for the at-PnBMA film with $28.2 \mathrm{~nm}$ thickness, $T_{\mathrm{g}}$ is around $21.5{ }^{\circ} \mathrm{C}$ (see the Supporting Information), ${ }^{49}$ is lower than the bulk producer's value $\left(29^{\circ} \mathrm{C}\right)$. Also, a recent report for PnBMA coatings formed by a grafted brush indicated $T_{\mathrm{g}}$ reduction by 5 deg. as the thickness decreased from 60 to 20 nm. ${ }^{27}$ The thickness-dependent $T_{\mathrm{g}}$ variation is smaller than the difference between temperatures used for isothermal experiments, and therefore, Figure 1 illustrates well the impact of varied polymer chain mobility (dependent on $\left(T-T_{\mathrm{g}}+50\right.$ $\mathrm{K})$ ).

To analyze dewetting of the iso-PnBMA layer in an aqueous solution, two phenomena must be considered-long-range dispersion interactions between the silicon oxide substrate (1) and the PBS solution (3) across the PnBMA layer (2) and short-range polar interactions between the PnBMA surface and water molecules, both contributing to the total excess free energy per unit area $\Delta G$ of the system.

$$
\Delta G=\frac{-A_{123}}{12 \pi h^{2}}+S^{\mathrm{P}} \exp \left(\frac{d_{0}-h}{l}\right)
$$

where $A_{123}$ is the effective Hamaker constant, $h$ is the PnBMA film thickness, $S^{\mathrm{p}}$ is the polar component of the spreading coefficient, $d_{0}$ is the atomic cutoff length, which is taken as $0.158 \mathrm{~nm}$, and $l$ is the correlation length. ${ }^{26}$

The dispersive interactions destabilize the layer when the Hamaker constant $\mathrm{A}_{123}$ is positive and stabilize it in the opposite case. The Hamaker constant may be calculated using the following equation

$$
A_{123}=24 \pi d_{0}^{2}\left(\gamma_{1}^{D}-\gamma_{2}^{D}\right)\left(\gamma_{3}^{D}-\gamma_{2}^{D}\right)
$$

where $\gamma_{i}^{D}$ is the dispersive component of the surface tension of phase $i$.

The polar surface tension components $\gamma^{\mathrm{P}}$, determined for iso- and at-PnBMA polymers, are similar within the experimental error (Table 1). Therefore, we do not expect differences in surface exposure between the polar and nonpolar side groups of both polymers ${ }^{50}$ that could significantly differentiate their wettabilities. In turn, based on the obtained values, the Hamaker constants can be analyzed for thin films of PnBMA with both tacticities. Applying eq 2 to both systems of iso- and at-PnBMA on the silicon oxide wafer in air $\left(\gamma_{3}^{\mathrm{D}}=0\right.$ $\mathrm{mN} / \mathrm{m}$ ), we obtain negative values of the Hamaker constant, indicating that van der Waals forces stabilize both types of polymer layers. Indeed, both iso- and at-PnBMA layers do not dewet in air at room temperature even after 3 months.

To analyze the dispersion forces for polymer layers immersed in aqueous solutions with eq 2 , the $\gamma^{\mathrm{D}}$ values determined for water and PBS (Table 1) can be used. The Hamaker constants, calculated with eq 2 for iso-PnBMA and at-PnBMA films on silicon and immersed in both liquids, are still negative. Hence, the long-range van der Waals forces stabilize the polymer layer.

Therefore, we conclude that another mechanism must be responsible for dewetting of the iso-PnBMA layer in PBS. As aqueous solutions are polar solvents, the destabilizing mechanism is most probably related to polar interactions. To evaluate the polar component $S^{\mathrm{P}}$ of the spreading coefficient $S$, we use the expression:

$$
S=S^{\mathrm{D}}+S^{\mathrm{P}}=\gamma_{23}\left(\cos \theta_{123}-1\right)
$$

where $S^{\mathrm{D}}$ is the dispersion component (equal to $-12 \pi \mathrm{d}_{0}{ }^{2} \mathrm{~A}_{123}$ ), $\gamma_{23}$ is the interfacial tension between the iso-PnBMA layer and PBS, and $\theta_{123}$ is the contact angle of the polymer on the silicon 

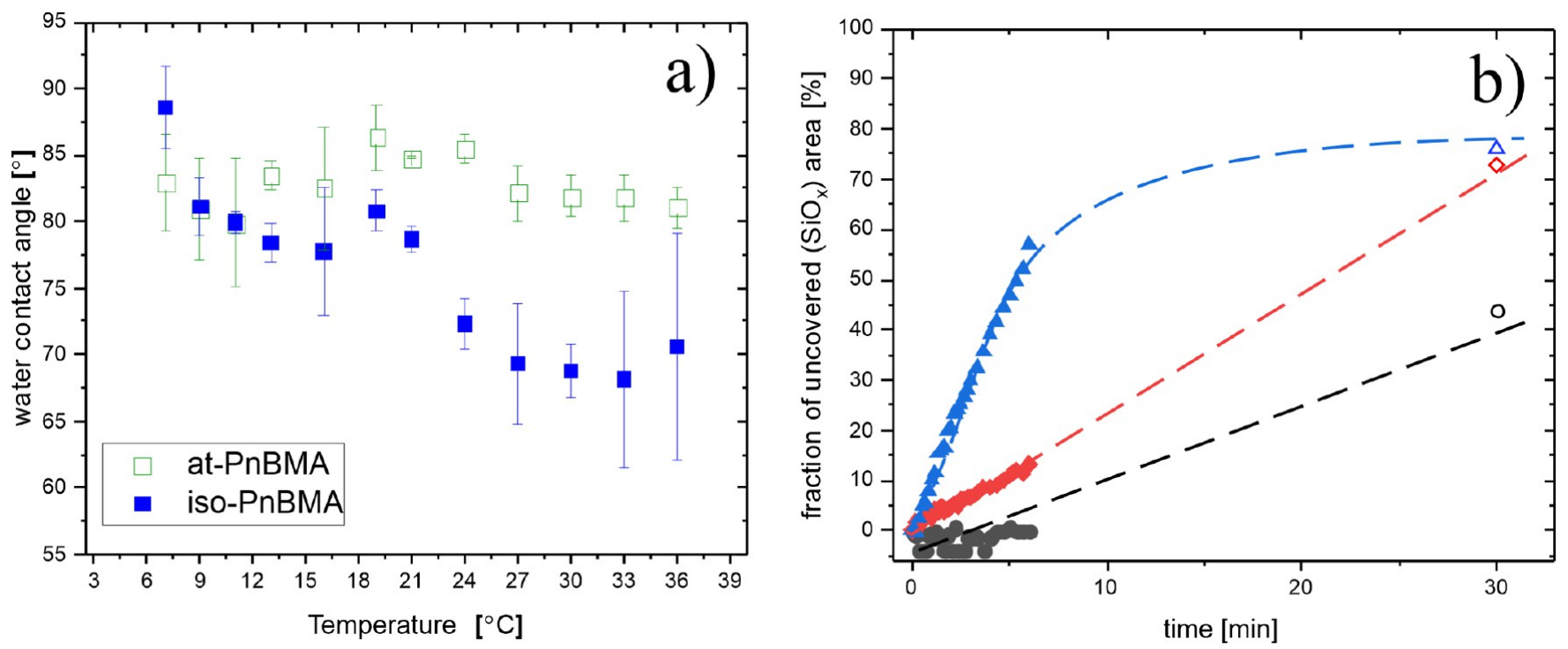

Figure 2. (a) Average water contact angles determined for at-PnBMA (green open squares, thickness $28.2 \mathrm{~nm}$ ) and iso-PnBMA films (blue solid squares, thickness $33.7 \mathrm{~nm}$ ) after exposure to a sessile droplet for times up to $45 \mathrm{sec}$. (b) Fraction $\mathrm{F}$ of uncovered $\mathrm{SiO}_{\mathrm{x}}$ areas determined for $(33.7$ nm thick) iso-PnBMA films exposed to aqueous PBS solutions, based on the wettability data analyzed with the Cassie equation (solid symbols) and optical images analyzed with the Minkowski measure F (open symbols) (Figure 5a), plotted as a function of exposure time for different temperatures (black: wettability at $7{ }^{\circ} \mathrm{C}$ and micrographs at $4{ }^{\circ} \mathrm{C}$; red: $21^{\circ} \mathrm{C}$, and blue: $37^{\circ} \mathrm{C}$ ). Dashed lines are guide to the eye.

oxide surface immersed in PBS. The contact angle $\theta_{123}$ is around 15 deg. was estimated from an AFM image ${ }^{51}$ (Figure S3). Additionally, $\gamma_{23}$ can be determined from the Young equation:

$$
\gamma_{2}=\gamma_{3} \cos \theta_{23 \text { air }}+\gamma_{23}
$$

where $\gamma_{2}$ is the surface tension of the polymer in air $\left(\gamma_{2}=\right.$ $\gamma_{\text {iso-PnBMA }}^{\mathrm{D}}+\gamma_{\text {iso-PnBMA }}^{\mathrm{P}}$ Table 1$), \gamma_{3}$ is the surface tension of the medium (water or PBS), and $\theta_{23 \text { air }}$ is the contact angle of the medium on the polymer $(\sim 80 \mathrm{deg}$. and $\sim 81 \mathrm{deg}$. for water and PBS, respectively). The spreading coefficients $S$ calculated using eqs 3 and 4 for iso-PnBMA immersed in water and PBS are equal to -0.65 and $-0.71 \mathrm{mN} / \mathrm{m}$, respectively. In turn, their $S^{\mathrm{P}}$ components, equal to -1.16 and $-0.92 \mathrm{mN} / \mathrm{m}$, respectively, describe the magnitude of polar interactions destabilizing the polymer film.

The presented analysis leads to the conclusion that the formation of the observed structures is caused by the interplay between the stabilizing long-range interactions between the silicon oxide substrate and the PBS solution across the isoPnBMA layer and the destabilizing polar interactions between the aqueous solution and iso-PnBMA. A similar process was observed also for other polymers, such as polystyrene and polyisoprene, in different solvents and classified as nonsolventinduced dewetting. ${ }^{21,26}$

3.3. Wettability of PnBMA Films in Water and PBS Solution. To examine how different tacticities of PnBMA and varied temperature affects the effective wettability of PnBMA films, contact angles of sessile water droplets were measured between 7 and $36^{\circ} \mathrm{C}$. The results, shown in Figure 2(a), show completely different behaviors of the two studied coatings after exposure to a sessile droplet, with stable at-PnBMA and dewetting iso-PnBMA films. The values of the water contact angle determined for a stable at-PnBMA film are almost constant for all analyzed temperatures. In contrast, for the isoPnBMA film, a strong impact of temperature is observed, reflecting the different temperature-dependent process of dewetting (see Figure $1 \mathrm{~d}-\mathrm{f}$ ) recorded at the time of measurement. According to the Cassie equation, ${ }^{52}$ the effective contact angle $\Theta_{\mathrm{e}}$ of a discontinuous iso-PnBMA layer depends on the area fractions of uncovered $\mathrm{SiO}_{\mathrm{x}}(\mathrm{F})$ and polymercovered regions $(1-\mathrm{F}), \cos \Theta_{\mathrm{e}}=\mathrm{F} \cos \Theta_{\mathrm{SiOx}}+(1-\mathrm{F})$

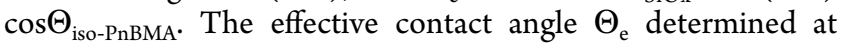
low temperatures is close to $85 \mathrm{deg}$., reflecting the $\Theta_{\text {iso-PnBMA }}$ value characteristic of the continuous iso-PnBMA film. However at higher temperatures, the $\Theta_{e}$ value is reduced considerably since dewetting is enhanced and a higher fraction $\mathrm{F}$ of the $\mathrm{SiO}_{\mathrm{x}}$ substrate, characterized by $\Theta_{\mathrm{SiOx}}(51 \pm 2)$ deg., is exposed.

To determine the temporal evolution of the dewettinginduced changes in surface composition, the wettability data obtained for the iso-PnBMA films exposed at different times (up to $6 \mathrm{~min}$ ) to aqueous PBS solutions were analyzed with the Cassie equation, as described above. Resulting values of the fraction $\mathrm{F}$ of the uncovered $\mathrm{SiO}_{\mathrm{x}}$ areas are plotted in Figure $2 \mathrm{~b}$ (solid symbols) as a function of exposure time for different temperatures (different colors). For comparison, the values of the fractional $\mathrm{SiO}_{\mathrm{x}}$ area $\mathrm{F}$ after 30 min of solution exposure are presented (open symbols), as determined using morphological measures from optical images (see Section 3.4). The dewetting kinetics at $21{ }^{\circ} \mathrm{C}$ and $37{ }^{\circ} \mathrm{C}$ can be compared using the characteristic times $\tau_{\mathrm{d}} \sim(45.0 \pm 0.9) \mathrm{min}$ and $(10.4 \pm 0.1)$ min, respectively, describing the linear temporal evolution of the uncovered $\mathrm{SiO}_{\mathrm{x}}$ area $\mathrm{F} \sim\left(\mathrm{t} / \tau_{\mathrm{d}}\right)$ determined from the wettability data. While the saturation of the uncovered $\mathrm{SiO}_{\mathrm{x}}$ area can be deduced after $\sim 20 \mathrm{~min}$ of dewetting at $37^{\circ} \mathrm{C}$, this cannot be claimed for the dewetting experiments performed at lower temperatures.

3.4. Dewetting of the Iso-PnBMA Films in PBS Solutions with Dissolved Proteins. Motivated by the dewetting behavior of an isotactic PnBMA layer cast on silicon and incubated in PBS, we decided to examine this process for protein solutions in PBS as a potential fabrication strategy for protein microarrays. For this purpose, we performed a series of experiments following incubation of isotactic PnBMA (with 
$\mathbf{T}=4^{0} \mathrm{C}$
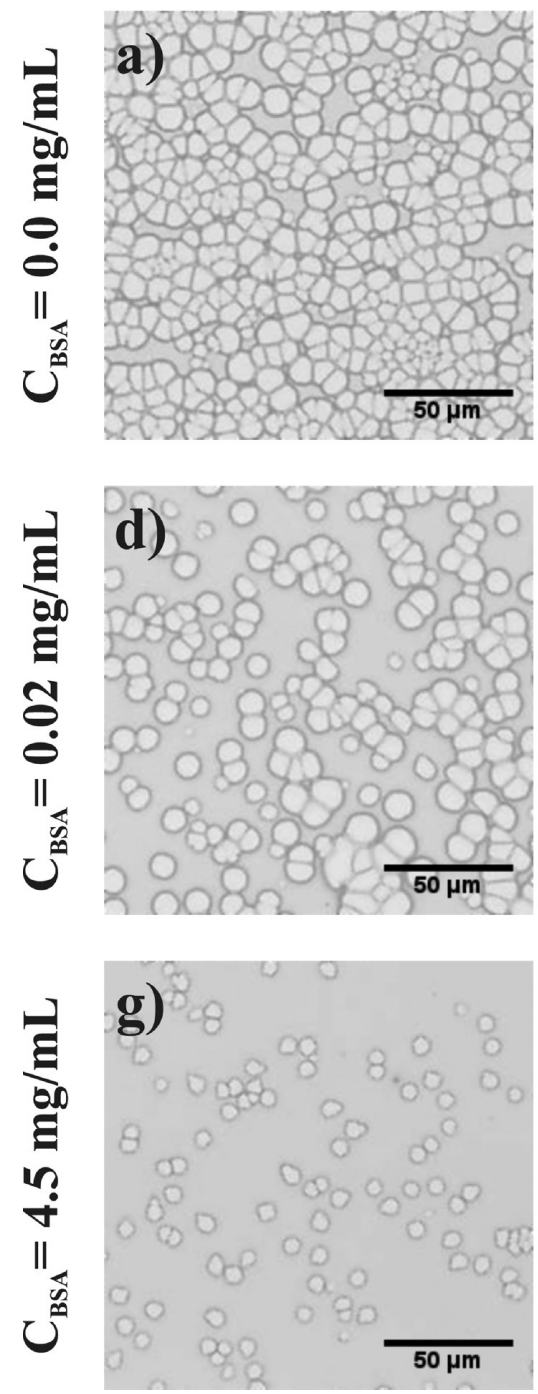

$\mathbf{T}=\mathbf{2 1}{ }^{\circ} \mathbf{C}$
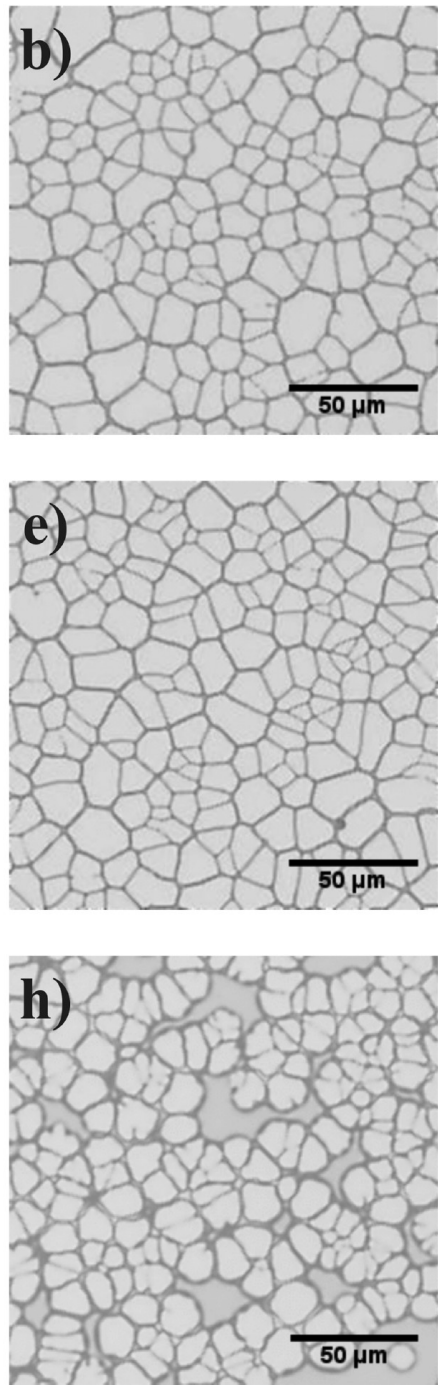

$\mathbf{T}=\mathbf{3 7 ^ { 0 } \mathbf { C }}$
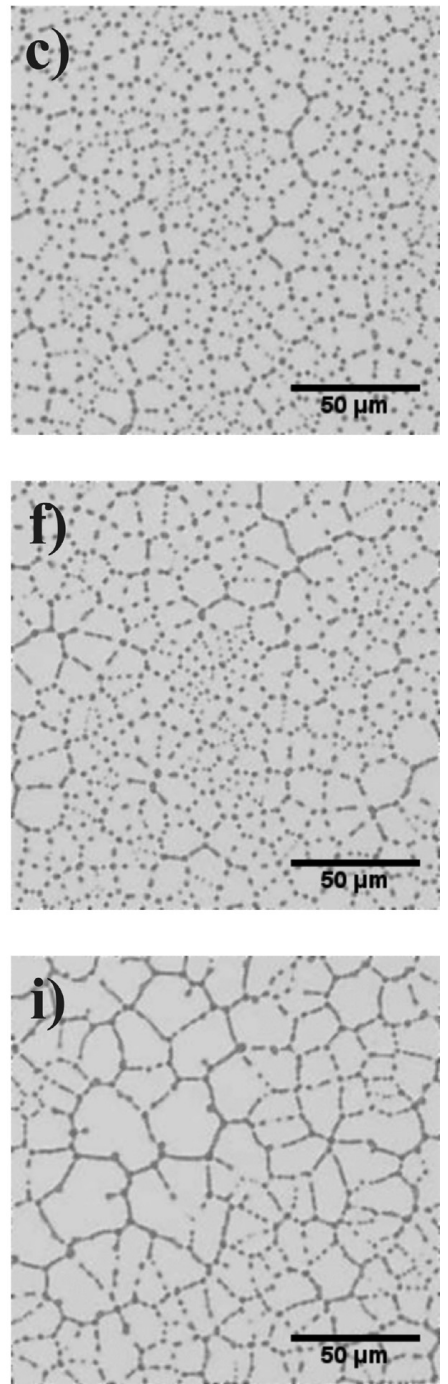

Figure 3. Optical images of the isotactic PnBMA layer (with thickness $\sim 34 \mathrm{~nm}$ ) after incubation in BSA solutions with concentrations equal to 0, 0.02 , and $4.5 \mathrm{mg} / \mathrm{mL}$ (rows) at 4,21 , and $37{ }^{\circ} \mathrm{C}$ (columns) for $30 \mathrm{~min}$.

thickness $\sim 34 \mathrm{~nm})$ in BSA solutions in PBS with three different concentrations $(0,0.02$, and $4.5 \mathrm{mg} / \mathrm{mL})$ and at three temperatures, equal to 4,21 , and $37{ }^{\circ} \mathrm{C}$.

The resulting surface images, shown in Figure 3, clearly depict the dewetting process for all considered experimental conditions. To compare quantitatively the structure of the dewetted iso-PnBMA films, Minkowski measures were calculated for the collected optical microscopy images (Figure 3 ). First, the collected images were transformed into representative black-and-white (binary) images (Figure 4) composed only of two types of surface regions: white-holes in the polymer film (uncovered silicon oxide) and blackpolymer film using the procedures described in our earlier papers. ${ }^{31-33}$ Next, each binary image was fully characterized by three morphological (Minkowski) measures. The obtained average values of the three Minkowski measures $(\langle F\rangle,\langle U\rangle$, and $\left.\left\langle\chi_{\mathrm{E}}\right\rangle\right)$, which characterize the morphology of the dewetted polymer films, are summarized in Table S1.

The overall characteristic of temperature dependence remains the same as for incubation in pure PBS and for both
BSA concentrations $\left(\mathrm{C}_{\mathrm{BSA}}\right)$, and the dewetting process is significantly better developed at elevated temperatures. The calculated average area fraction $\langle\mathrm{F}\rangle$ of holes (Figure 5a) shows an increment from $(44 \pm 1) \%$ to $(76 \pm 2) \%$ for PBS and from $(6 \pm 1) \%$ to $(80 \pm 1) \%$ for the highest concentration of BSA with increasing temperature. However, there is a significant difference between the structures observed for a given temperature for samples incubated in the BSA solution with a low and high concentration. At $4{ }^{\circ} \mathrm{C}$, the iso-PnBMA layer incubated in pure PBS is covered with dense holes $(\langle\mathrm{F}\rangle=(44$ $\pm 1) \%)$, which start to coalescence, whereas with increasing BSA concentration, much more sparse, separated holes are observed and the holes area fraction decreases to $(25 \pm 1) \%$ and $(6 \pm 1) \%$ for $0.02 \mathrm{mg} / \mathrm{mL}$ and $4.5 \mathrm{mg} / \mathrm{mL}$ of BSA, respectively. Moreover, the Euler parameter (which describes the amount of isolated white islands observed on images and related to holes in the polymer layer) (Figure $5 \mathrm{~b}$ ) changes from $415 \pm 28$ for PBS to $184 \pm 30$ and $102 \pm 6$ for $\mathrm{C}_{\mathrm{BSA}}$ equal $0.02 \mathrm{mg} / \mathrm{mL}$ and $4.5 \mathrm{mg} / \mathrm{mL}$, respectively. This clearly indicates that the amount of holes as well as the dewetted area 

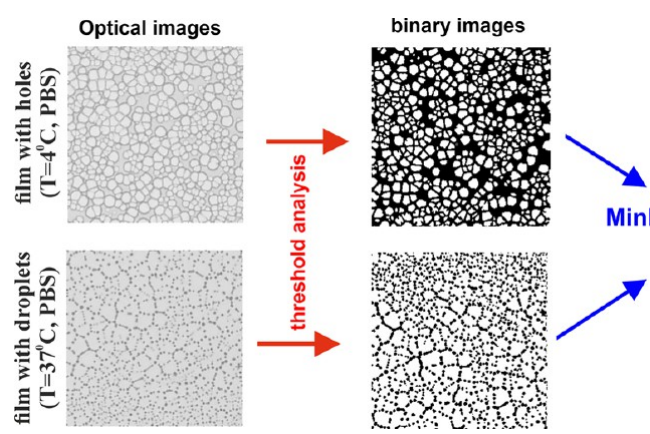

Minkowski measures

$\left(\mathbf{F}, \mathbf{U}, \mathbf{X}_{\mathbf{E}}\right)$

Figure 4. Representative optical images transformed with threshold analysis into black-and-white images. Each pixel is reset to either white or black depending on whether its local gray level value is greater or lower than the threshold variable specified by dominant gray. ${ }^{32}$ Each black-and-white image reflects surface patterns with white and black regions corresponding to the uncovered silicon oxide and the polymer-covered area, respectively. Such binary images are characterized by three Minkowski measures: the white area fraction $\mathrm{F}$ and its boundary length $\mathrm{U}$, as well as the Euler characteristic $\chi_{\mathrm{E}}$, defined as the difference between the number of separated white and black features. In our dewetting experiments, surface patterns dominated by holes and droplets, respectively, are described by positive and negative $\chi_{\mathrm{E}}$ values.

decrease with increasing protein concentrations. With the temperature of incubation elevated to $21^{\circ} \mathrm{C}$, polygonal patterns are already formed for $\mathrm{C}_{\mathrm{BSA}}=0 \mathrm{mg} / \mathrm{mL}$ and 0.02 $\mathrm{mg} / \mathrm{mL}$, with the holes area fraction of $\sim 73 \%$ (which accords with the value estimated from contact angle measurements using the Cassie equation), while the holes are still in the stage of coarsening for the $4.5 \mathrm{mg} / \mathrm{mL}$ one $(\langle\mathrm{F}\rangle=(46 \pm 6) \%)$. Finally, at $37^{\circ} \mathrm{C}$, the rims decay into spherical droplets and the Euler parameter values change into negative, indicating rim breaking and polymer droplet formation. However, this process is more advanced for samples incubated in pure PBS $\left\langle\chi_{\mathrm{E}}\right\rangle=750 \pm 140$ than those incubated in BSA solutions $\left(\left\langle\chi_{\mathrm{E}}\right\rangle\right.$ $=585 \pm 73$ and $\left\langle\chi_{\mathrm{E}}\right\rangle=277 \pm 77$ for $\mathrm{C}_{\mathrm{BSA}}$ equal $0.02 \mathrm{mg} / \mathrm{mL}$ and $4.5 \mathrm{mg} / \mathrm{mL}$, respectively). These results strongly imply that it is possible to slow down the dewetting process simply by increasing the amount of BSA in the solution.

To verify this hypothesis, additional tests were conducted, where iso-PnBMA layers were incubated at $21{ }^{\circ} \mathrm{C}$ in BSA solutions $\left(C_{\mathrm{BSA}}\right)$ with five different protein concentrations, equal to $0.02,0.1,0.5,1$, and $4.5 \mathrm{mg} / \mathrm{mL}$.

The surface images recorded using an optical microscope (Figure S4) confirm the previous observations. The dewetting process proceeds much slower for samples incubated in PBS solutions with a higher protein concentration. For a BSA concentration of 0.02 , polygonal patterns are observed. In turn, for protein concentrations ranging from 0.1 to $4.5 \mathrm{mg} / \mathrm{mL}$, individual holes accompanying the small polygonal structures are still present, indicating the much earlier stage of dewetting. The remnant, not structured plateau areas of the PnBMA layer are visible mainly for the largest BSA concentration. This is clearly represented by the Minkowski measures (Figure 6). The uncovered area of $\mathrm{SiO}_{x}$ (Figure 6a) decreases from $\sim 73$ to $\sim 45 \%$ with increasing $C_{\mathrm{BSA}}$. Moreover, the average area of holes (Figure 6b) observed in the optical images (Figure S4) is the greatest for $C_{\mathrm{BSA}}=0$ and $0.02 \mathrm{mg} / \mathrm{mL}$ and then decreases almost two times for higher protein concentrations. Also the topographical images, recorded with an AFM (Figure 7), show the flat, elevated areas between the polygonal rims, already for a BSA concentration of $0.5 \mathrm{mg} / \mathrm{mL}$. The AFM images also determine the nanotopography of the polymer plateau edges ( $\sim 3 \mu \mathrm{m}$ wide and $\sim 50 \mathrm{~nm}$ high) facing the holes (Figure $7 \mathrm{~b}$ ) and the polygonal continuous rims $(\sim 2 \mu \mathrm{m}$ wide and $\sim 100 \mathrm{~nm}$ high).

This effect may have two possible explanations. First, the polar interactions between the polymer layer and the liquid environment may be weakened when proteins are added to the solution. Second, proteins adsorbed to the dewetted surface may retard or even block the dewetting process.

To verify the first hypothesis, we use the estimated dispersive components of surface tension $\gamma^{\mathrm{D}}$ of BSA solutions (Table 2) to analyze with eq. 2 the sign and magnitude of the Hamaker constant. Its negative value and growing absolute magnitude with protein concentration can be concluded, indicating that the stabilizing dispersion interactions are
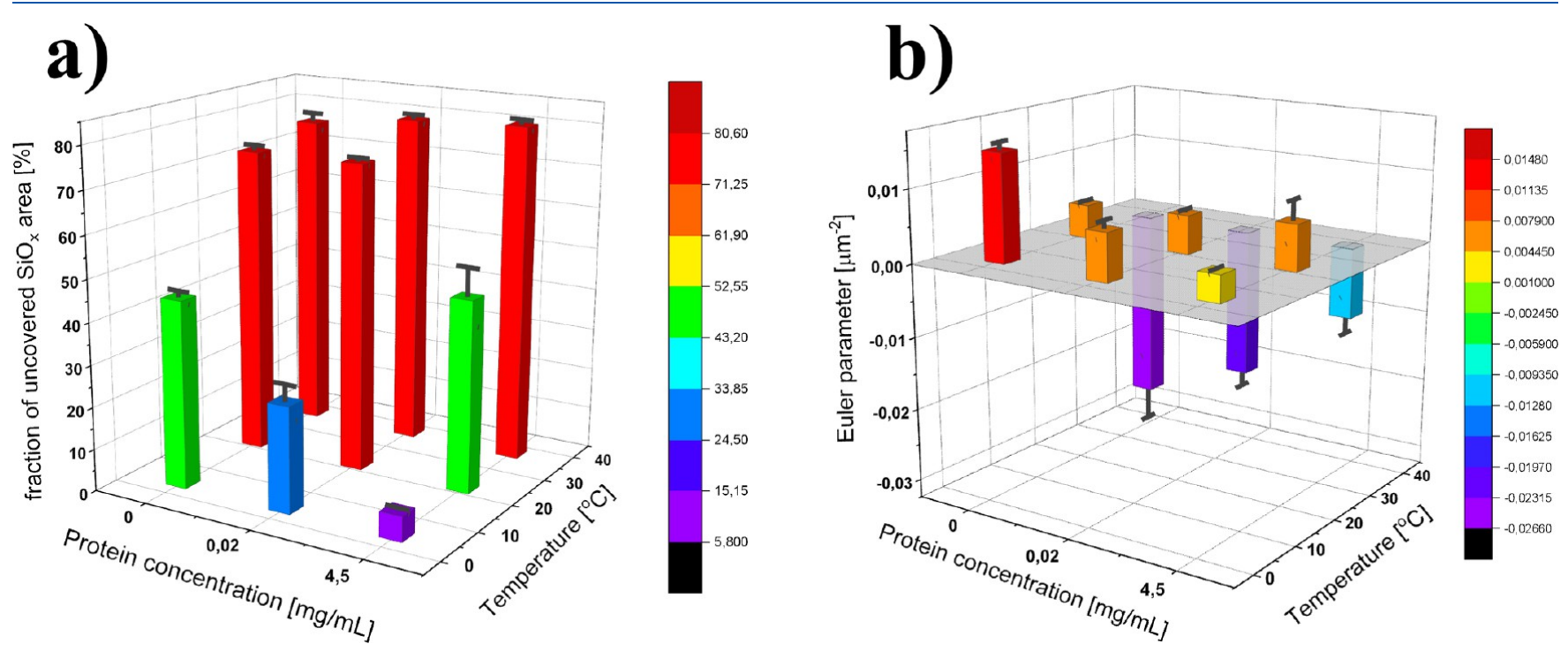

Figure 5. (a) Fraction of uncovered area (F) and (b) Euler parameter plotted as a function of temperature and BSA concentration in dewetting experiments. 

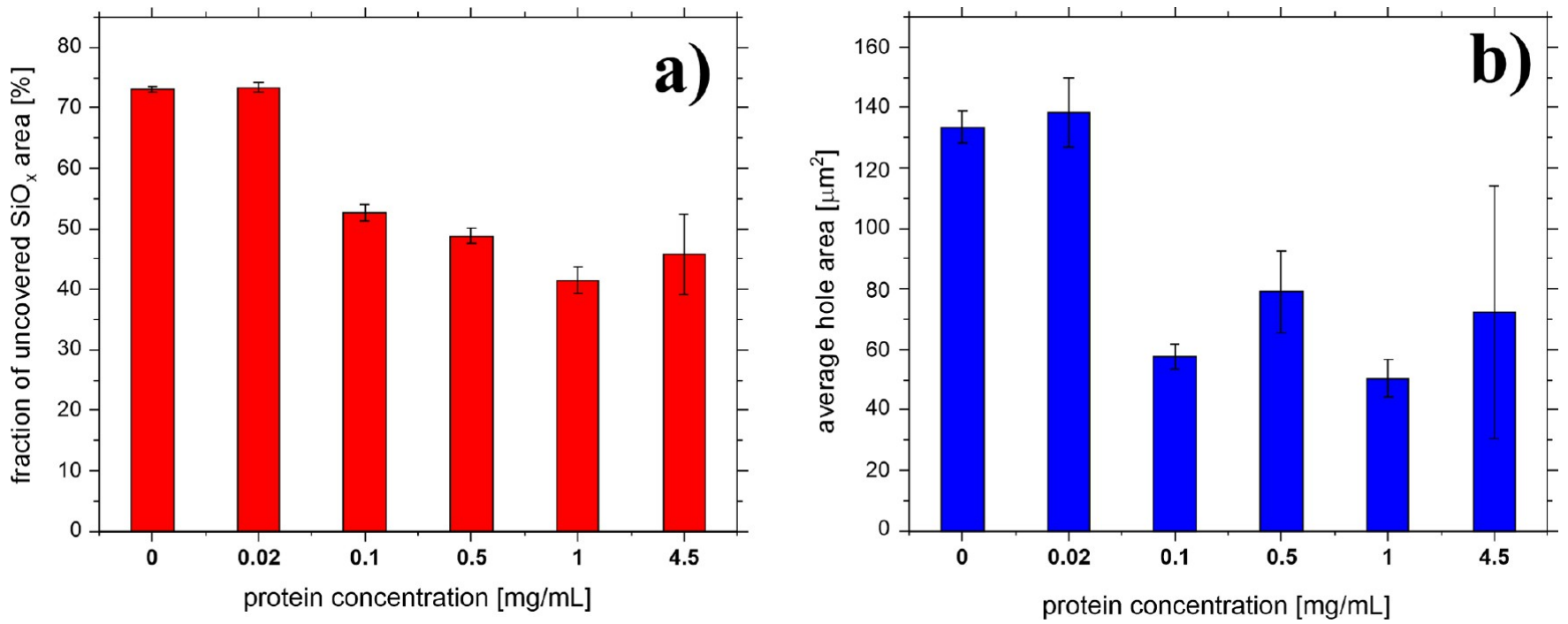

Figure 6. (a) Fraction of uncovered area, that is, holes, (F) and (b) average area of the individual surface feature, that is, hole, $(F) /\left(\chi_{\mathrm{E}}\right)$ plotted as a function of BSA concentration for dewetting experiments performed at $21{ }^{\circ} \mathrm{C}$ (please see Table S2).
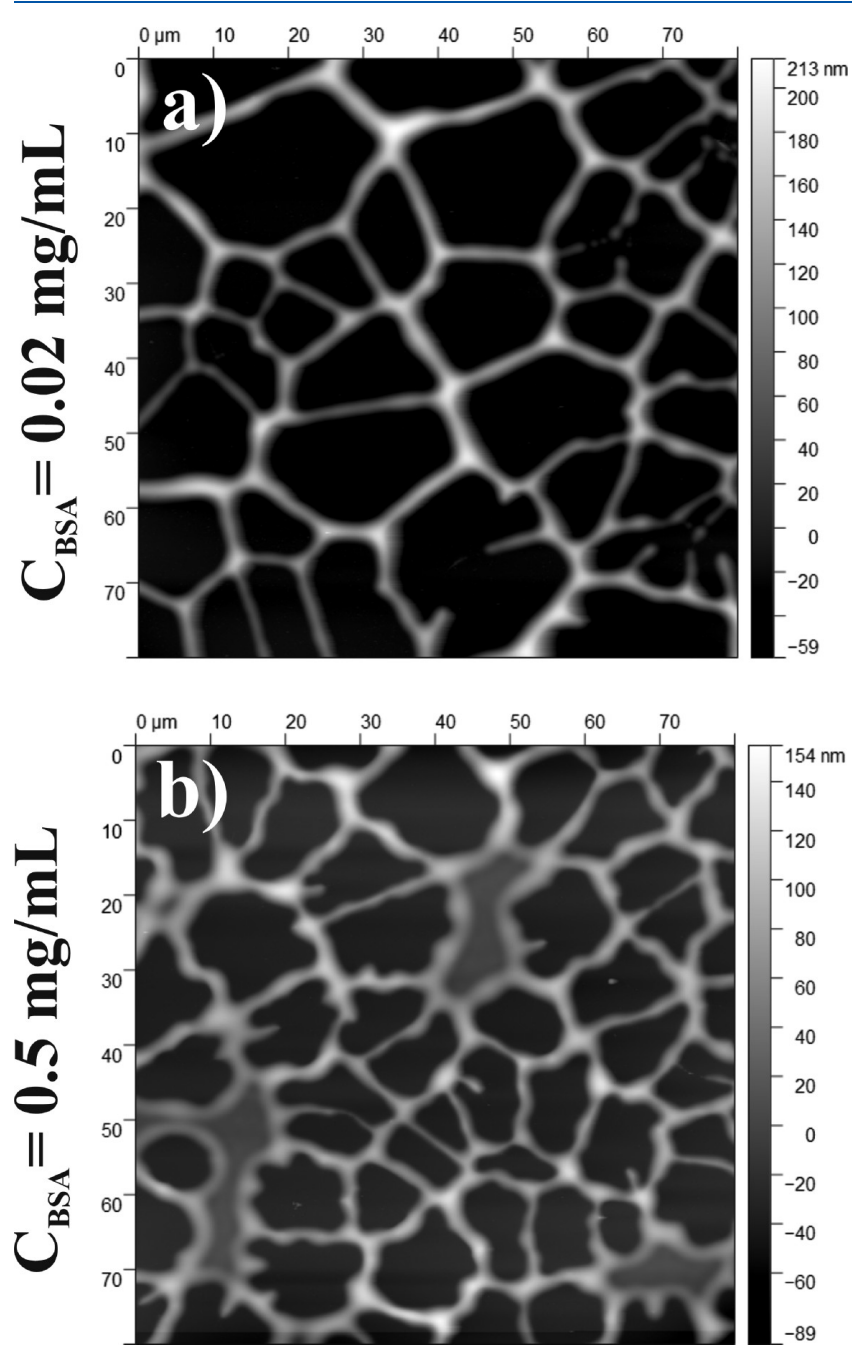

Figure 7. AFM images of the isotactic PnBMA layer after incubation in BSA solutions with concentrations equal to 0.02 and $0.5 \mathrm{mg} / \mathrm{mL}$ at $21{ }^{\circ} \mathrm{C}$ for $30 \mathrm{~min}$.

enhanced by BSA addition to PBS solutions. Still, the negative spreading coefficients $S$ are expected and evaluated with eqs 3 and 4 using the determined contact angles of PBS solutions on the polymer $\left(\theta_{23 \mathrm{air}}=87.3,91.8\right.$, and 94.9 degree for $C_{\mathrm{BSA}}=$ $0.02,0.1$, and $4.5 \mathrm{mg} / \mathrm{mL}$, respectively). The spreading coefficient $S$ varies between -0.96 and $-1.25 \mathrm{mN} / \mathrm{m}$ with increasing protein concentration. Therefore, a stronger dependence with $C_{\mathrm{BSA}}$ of the destabilizing polar interactions is concluded, as indeed revealed by the estimated polar component values of the spreading coefficients, with $S^{\mathrm{P}}$ equal to -1.0 and $-2.3 \mathrm{mN} / \mathrm{m}$, respectively, for $C_{\mathrm{BSA}}$ equal to 0.02 and $4.5 \mathrm{mg} / \mathrm{mL}$. Therefore, the first hypothesis that the polar interactions between the polymer layer and the liquid environment are weakened by the dissolved proteins should be rejected.

3.5. Protein Adsorption on Dewetted Surfaces Analyzed with ToF-SIMS. To verify the second hypothesis that polymer dewetting can be hindered by protein adsorption, the adsorbed proteins were analyzed with ToF-SIMS, taking advantage of their chemical specificity and surface sensitivity. For the applied setup, the surface sensitivity of ToF-SIMS is described by the exponential decay of the signal intensity as a function of organic overlayer thickness, with an attenuation depth of $\lambda=0.63( \pm 0.10) \mathrm{nm}$, that enables us to probe even the complete protein monolayer (the "escape" depth of secondary ions of $\sim 3.0 \mathrm{~nm}$ corresponds to a uniform protein layer with a surface density of $\left.\sim 3.8 \mathrm{mg} / \mathrm{m}^{2}\right) .{ }^{53}$ The ToF-SIMS chemical images of iso-PnBMA films on the $\mathrm{SiO}_{x}$ substrate incubated in PBS solutions of the BSA protein with two different concentrations, $C_{\mathrm{BSA}}=0.02$ and $1 \mathrm{mg} / \mathrm{mL}$, are shown in Figure $8 \mathrm{a}-\mathrm{c}$ and $\mathrm{d}-\mathrm{f}$, respectively. The images recorded with ions characteristic of the iso-PnBMA polymer $\left(\mathrm{C}_{4} \mathrm{H}_{5} \mathrm{O}_{2}{ }^{-}\right)$ and the BSA protein $\left(\mathrm{CNO}^{-}\right)$clearly demonstrate that $\mathrm{BSA}$ is adsorbed preferentially to the uncovered silicon oxide areas compared to the polymer-covered regions (cf. Figure $8 \mathrm{~d}$ and e). Since the ToF-SIMS signal intensities show a linear correlation with the organic surface composition, ${ }^{54}$ the surface amount of the BSA protein on uncovered silicon oxide areas is evaluated (for $C_{\mathrm{BSA}}=1 \mathrm{mg} / \mathrm{mL}$ ) to be 4.6 times larger than that on the PnBMA-covered areas. Also, the thickness of BSA layers on uncovered regions does not exceed that of the protein monolayer, as signaled by the signals characteristic of the substrate $\left(\mathrm{SiO}_{2}^{-}\right.$and $\left.\mathrm{SiHO}_{2}^{-}\right)$. Finally, based on the ToF- 
a)

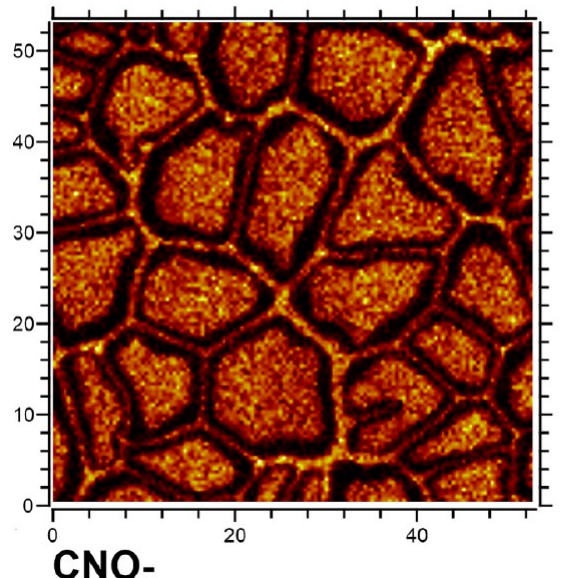

d)

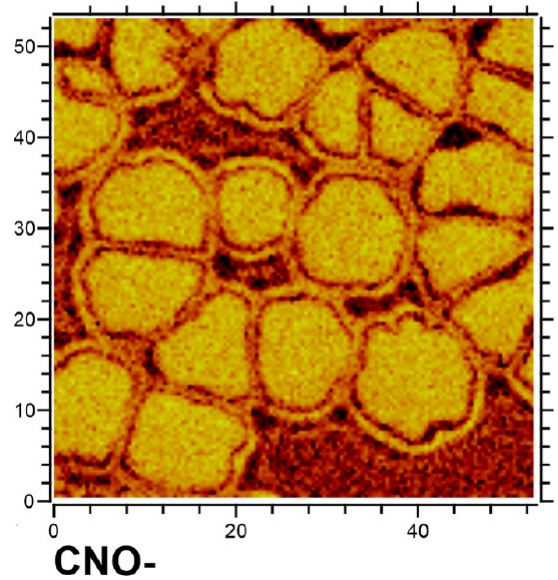

b)

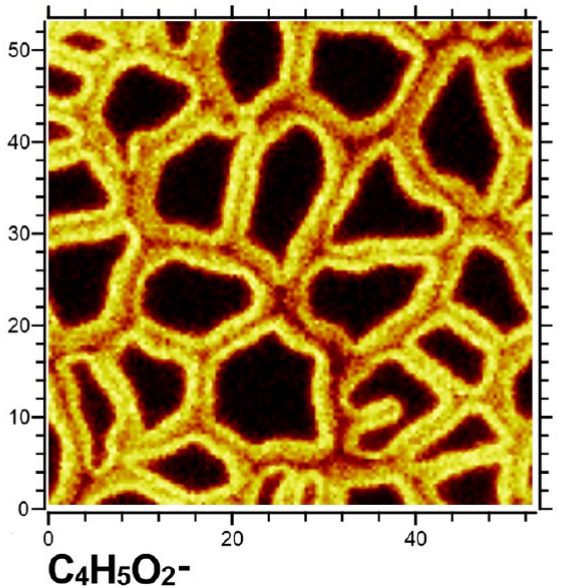

e)

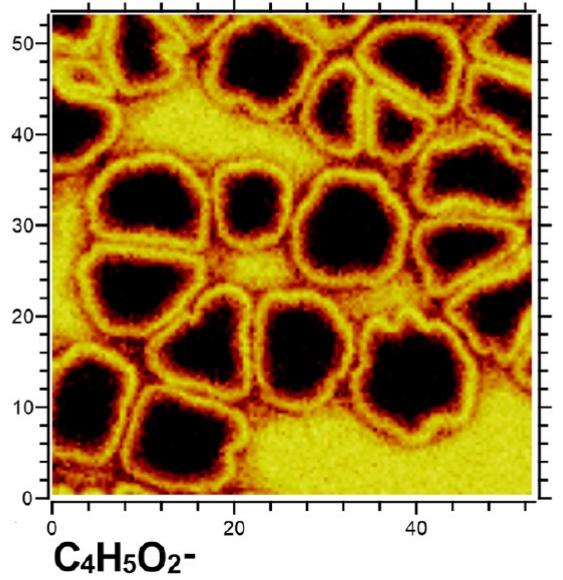

c)
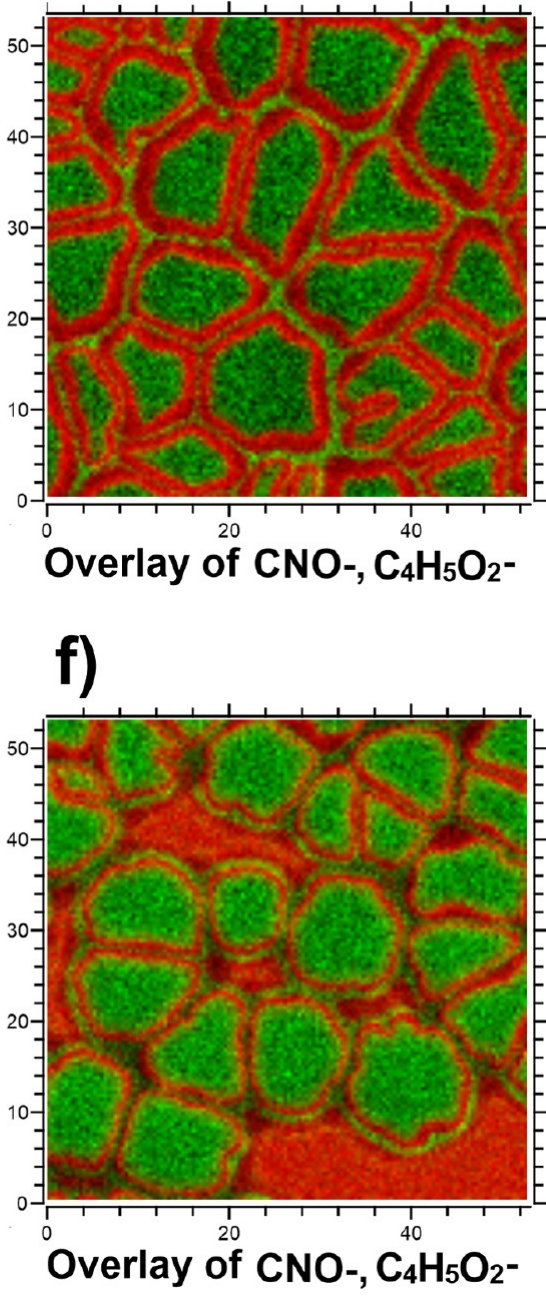

Figure 8. (a,b and d,e) ToF-SIMS chemical images and (c, f) color-coded composite images of iso-PnBMA films incubated in PBS solutions with BSA concentrations, $(\mathrm{a}-\mathrm{c}) \mathrm{C}_{\mathrm{BSA}}=0.02$ and $(\mathrm{d}-\mathrm{f}) 1 \mathrm{mg} / \mathrm{mL}$. Maps of $(\mathrm{a}, \mathrm{d})$ BSA and $(\mathrm{e}, \mathrm{f})$ iso-PnBMA distribution using ions characteristic of a protein $\left(\mathrm{CNO}^{-}\right)$and a polymer $\left(\mathrm{C}_{4} \mathrm{H}_{5} \mathrm{O}_{2}^{-}\right)$. Color-coded composite maps of surface components, red: iso-PnBMA polymer $\left(\right.$using $\left.\mathrm{C}_{4} \mathrm{H}_{5} \mathrm{O}_{2}{ }^{-}\right)$and green: BSA protein (using $\mathrm{CNO}^{-}$).

SIMS examination of the samples incubated in different protein solutions, we determined the relative amount of protein adsorbed on $\mathrm{SiO}_{x}$ plotted as a function of $\mathrm{BSA}$ concentration $C_{\mathrm{BSA}}$ (Figure 9).

In addition to preferential BSA adsorption to uncovered $\mathrm{SiO}_{x}$ regions compared to the polymer-covered areas, ToFSIMS data point to an interfacial BSA activity. The chemical maps of iso-PnBMA and BSA surface components (Figure 8), and in particular, their color-coded composite representations (Figure $8 \mathrm{c}$ and $\mathrm{f}$ ) reveal enhanced $\mathrm{BSA}$ (green, $\mathrm{CNO}^{-}$signal) presence in the regions close to the contact line of the three phases, that is, on the polymer plateau edges facing holes (Figure 8f) and at continuous rims (Figure $8 \mathrm{c}$ and f). Preferential adsorption close to a hydrophilic/hydrophobic interface $\gamma_{\mathrm{SiO}_{x}}^{\mathrm{P}} / \gamma_{\text {iso-PnBMA }}^{\mathrm{P}}=13.2 / 1.2$ can be related to the amphiphilic nature of protein molecules, ${ }^{55}$ rearranging their polar and nonpolar residues at the interface. ${ }^{56}$ Enhanced protein adsorption at hydrophilic/hydrophobic interfaces, PS/ $\mathrm{PMMA}^{57}$ or PS/PNVP, ${ }^{14}$ was reported previously. Also, other effects related to modified surface nanotopography (e.g., curvature, roughness, and specific surface features) can be involved, but their exact impact on the protein adsorption process is not fully understood. ${ }^{29,58}$ A careful inspection of the reports on protein adsorption on the surfaces modified earlier by dewetting reveals surface features of protein patterns (separate rings around the protein-covered holes) resembling those of Figure $8 \mathrm{f}$ but with no spatial correlations between the polymer and the protein. ${ }^{13,59}$

3.6. Polymer Dewetting Hindered by Protein Adsorption. Inhibition of polymer dewetting is stronger for the polymer films exposed to solutions with a higher protein concentration $C_{\mathrm{BSA}}$ (Section 3.4), when larger protein adsorption is observed (Figure 9). In fact, the ToF-SIMS results revealed BSA proteins adsorbed to various regions of the dewetted surface, with the data corresponding to $30 \mathrm{~min}$ of film incubation at $21{ }^{\circ} \mathrm{C}$. The kinetics of dewetting are slower than those of protein adsorption. The former is described at 21 ${ }^{\circ} \mathrm{C}$ (see Figure 2b) as a linear temporal development of fractional uncovered $\mathrm{SiO}_{x}$ area $F \sim\left(\mathrm{t} / \tau_{\mathrm{d}}\right)$ with a characteristic time of $\tau_{\mathrm{d}} \sim(45.0 \pm 0.9) \mathrm{min}$. The latter is estimated from the kinetics of BSA adsorption determined (under the same conditions) for the isomer (nondewetting) polymer PnBMA, $\sim\left(1-\exp \left(-\mathrm{t} / \tau_{\mathrm{a}}\right)\right)$, and characterized by a specific time of $\tau_{\mathrm{a}}$ 


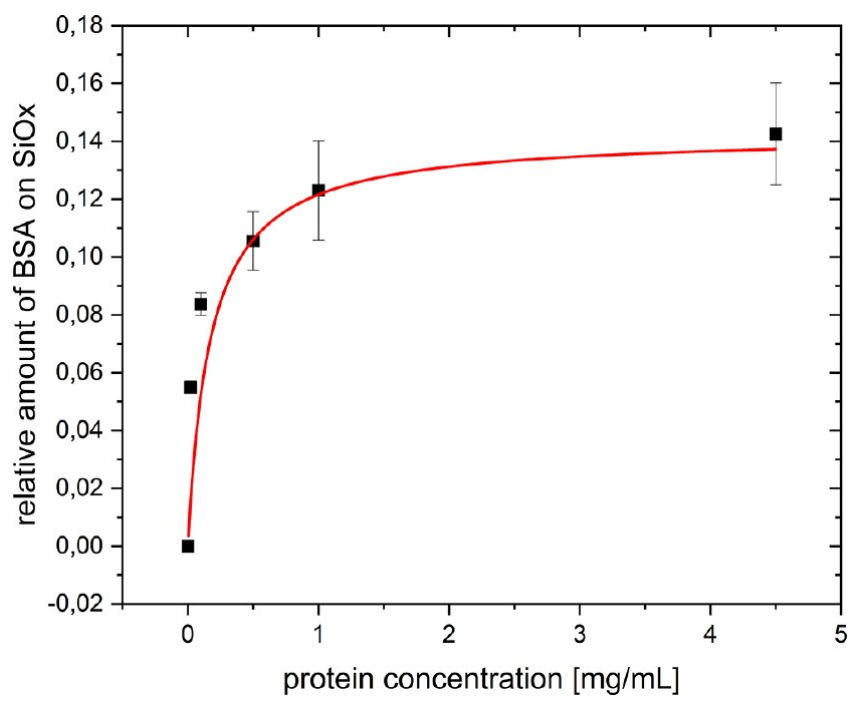

Figure 9. Relative amount of $\mathrm{BSA}$ adsorbed on uncovered $\mathrm{SiO}_{x}$ areas, evaluated from the $\mathrm{CNO}^{-}$signal intensity, plotted as a function of BSA concentration $C_{\mathrm{BSA}}$.

$\sim 2.2 \mathrm{~min}$. Therefore, the recorded dewetting data correspond to the adsorbed protein layers in local equilibrium, specified for various surface regions $\left(\mathrm{SiO}_{x}, \mathrm{PnBMA}\right.$, and regions close to the three-phase line).

Several strategies for the inhibition of dewetting of polymer films have been developed, resulting from thermodynamic and kinetic considerations due to change in the surface energy and polymer mobility, respectively, but precise mechanisms have often eluded precise description. ${ }^{3}$ The so far reported strategies rely on modification of the substrate or the polymer film (including cross-linking) and on application of additives to the polymer. The presented results here suggest a novel strategy based on the additive (BSA) applied to the liquid surrounding both the substrate and the polymer. Relevant mechanisms might be related to proteins adsorbed to various regions of the dewetted surface. For instance, since the adsorbed BSA layer is formed on $\mathrm{SiO}_{x}$, the spreading coefficient $S$ specified in eq 3 as the difference of surface energy of the bare $\mathrm{SiO}_{x}$ substrate and polymer-wetted $\mathrm{SiO}_{x}$ must be modified. The free energy change $S$ for spreading the polymer over $\mathrm{SiO}_{x}$ should be reduced by the positive coefficient $S^{\prime}$ for the spreading of BSA over the $\mathrm{SiO}_{x}$ surface. The dewetting driving force can be also reduced when the polymer/liquid surface tension $\gamma_{23}$ is decreased, for example, due to adsorption of amphiphilic BSA molecules. This might reduce the capillary force counterbalanced by viscous dissipation, leading to a lower dewetting velocity. ${ }^{60}$ In turn, kinetic considerations suggest pinning sites, for example, formed due to the interfacial activity of amphiphilic BSA that can try to arrest the three-phase contact line.

\section{CONCLUSIONS}

In this work, the stability of thin polymer layers composed of isotactic and atactic PnBMA was examined. We show that both layers are stable in the atmosphere; however, the nonsolvent dewetting process is observed for iso-PnBMA after immersion in PBS due to the $T_{\mathrm{g}}$ value, much lower than for at-PnBMA. In the next step, analogous experiments were performed for isoPnBMA films exposed to PBS solutions with different concentrations $C_{\mathrm{BSA}}$ of the model protein (BSA). The results obtained at different temperatures close to the physiological limit (between 4 and $37^{\circ} \mathrm{C}$ ) show that the dewetting process is significantly slowed down for higher $C_{\mathrm{BSA}}$. The explanation of these observations is the adsorption of BSA molecules to various regions of the dewetted surface, with spatial correlation between the protein and the dewetted polymer evidenced by ToF-SIMS. Therefore, this work suggests a novel strategy to hinder polymer dewetting based on the additive (protein) added to the phase (liquid) surrounding both the substrate and the polymer. ToF-SIMS evidences also preferential protein adsorption on uncovered $\mathrm{SiO}_{x}$ regions. This shows that the one-step procedure, involving polymer dewetting accompanied by protein adsorption, can be used for protein microarray fabrication. In addition, the increased protein surface concentration on elevated polymer regions such as formed rims points to nanotopography effects in protein adsorption.

\section{ASSOCIATED CONTENT}

\section{Supporting Information}

The Supporting Information is available free of charge at https://pubs.acs.org/doi/10.1021/acs.langmuir.0c01718.

Calculated polar and dispersive components of surface energy for different solutions; optical images of atactic and isotactic PnBMA layers after incubation in PBS at 4, 21, and $37{ }^{\circ} \mathrm{C}$ for $30 \mathrm{~min}$; AFM image of iso-PnBMA incubated in PBS; Minkowski measures calculated for iso-PnBMA incubated in different concentrations of BSA in PBS solution at different temperatures; optical images of the isotactic PnBMA layer after incubation in BSA solution with concentrations equal to $0.02,0.1,0.5,1$, and $4.5 \mathrm{mg} / \mathrm{mL}$ at $21{ }^{\circ} \mathrm{C}$ for $30 \mathrm{~min}$ and the corresponding Minkowski measures; and thickness versus temperature profile of the at-PnBMA film (PDF)

\section{AUTHOR INFORMATION}

\section{Corresponding Authors}

Andrzej Budkowski - M. Smoluchowski Institute of Physics, Jagiellonian University, 30-348 Krakow, Poland; 이이.org/ 0000-0001-5200-3199; Phone: +48 12664 4557; Email: andrzej.budkowski@uj.edu.pl; Fax: +48 126644905

Kamil Awsiuk - M. Smoluchowski Institute of Physics, Jagiellonian University, 30-348 Kraków, Poland; 다. orcid.org/ 0000-0001-9058-4561; Email: kamil.awsiuk@uj.edu.pl

\section{Authors}

Natalia Janiszewska - M. Smoluchowski Institute of Physics, Jagiellonian University, 30-348 Krakow, Poland; ㅇorcid.org/ 0000-0001-5042-1848

Joanna Raczkowska - M. Smoluchowski Institute of Physics, Jagiellonian University, 30-348 Kraków, Poland; 이이.org/ 0000-0002-2307-4614

Katarzyna Gajos - M. Smoluchowski Institute of Physics, Jagiellonian University, 30-348 Kraków, Poland

Yurij Stetsyshyn - Lviv Polytechnic National University, 79013

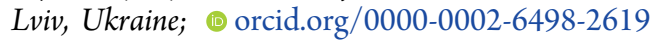

Maciej Michalik - M. Smoluchowski Institute of Physics, Jagiellonian University, 30-348 Kraków, Poland

Complete contact information is available at: https://pubs.acs.org/10.1021/acs.langmuir.0c01718 


\section{Notes}

The authors declare no competing financial interest.

\section{ACKNOWLEDGMENTS}

This work was financially supported by the National Science Center of Poland under Grants No. UMO-2016/21/D/ST5/ 01633. Equipment was purchased, thanks to the financial support of the European Regional Development Fund (POIG.02.01.00-12-023/08) and the European Regional Development Fund Operational Program on Infrastructure and Environment (POIS 13.01.00-00-062/08).

\section{REFERENCES}

(1) Higgins, A. M.; Sferrazza, M.; Jones, R. A. L.; Jukes, P. C.; Sharp, J. S.; Dryden, L. E.; Webster, J. The Timescale of Spinodal Dewetting at a Polymer/Polymer Interface. Eur. Phys. J. E: Soft Matter Biol. Phys. 2002, 8, 137-143.

(2) Gentili, D.; Foschi, G.; Valle, F.; Cavallini, M.; Biscarini, F. Applications of Dewetting in Micro and Nanotechnology. Chem. Soc. Rev. 2012, 41, 4430-4443.

(3) Xue, L.; Han, Y. Inhibition of Dewetting of Thin Polymer Films. Prog. Mater. Sci. 2012, 57, 947-979.

(4) Wyart, F. B.; Martin, P.; Redon, C. Liquid/Liquid Dewetting. Langmuir 1993, 9, 3682-3690.

(5) Redon, C.; Wyart, F. B.; Rondelez, F. Dynamics of Dewetting. Sci. Direct 1991, 369, 141.

(6) Bull, S. J. Analysis Methods and Size Effects in the Indentation Fracture Toughness Assessment of Very Thin Oxide Coatings on Glass. Comptes Rendus Mécanique 2011, 339, 518-531.

(7) Wang, C.; Krausch, G.; Geoghegan, M. Dewetting at a PolymerPolymer Interface: Film Thickness Dependence. Langmuir 2001, 17, 6269-6274.

(8) Seemann, R.; Herminghaus, S.; Jacobs, K. Gaining Control of Pattern Formation of Dewetting Liquid Films. J. Phys. Condens. Matter 2001, 13, 4925-4938.

(9) Müller-Buschbaum, P.; Gutmann, J. S.; Lorenz-Haas, C.; Wunnicke, O.; Stamm, M.; Petry, W. Dewetting of Thin Diblock Copolymer Films: Spinodal Dewetting Kinetics. Macromolecules 2002, 35, 2017-2023.

(10) Becker, J.; Grün, G.; Seemann, R.; Mantz, H.; Jacobs, K.; Mecke, K. R.; Blossey, R. Complex Dewetting Scenarios Captured by Thin-Film Models. Nat. Mater. 2003, 2, 59-63.

(11) Al Akhrass, S.; Reiter, G.; Hou, S. Y.; Yang, M. H.; Chang, Y. L.; Chang, F. C.; Wang, C. F.; Yang, A. C. M. Viscoelastic Thin Polymer Films under Transient Residual Stresses: Two-Stage Dewetting on Soft Substrates. Phys. Rev. Lett. 2008, 100, 1-4.

(12) David, M. O.; Reiter, G.; Sittha1, T.; Schulz, J.; Sitthaï, T.; Schultz, J.; Sittha1, T.; Schulz, J. Deformation of a Glassy Polymer Film by Long-Range Intermolecular Forces. Langmuir 1998, 14, 5667-5672.

(13) Neto, C. A Novel Approach to the Micropatterning of Proteins Using Dewetting of Polymer Bilayers. Phys. Chem. Chem. Phys. 2007, 9, 149-155.

(14) Thickett, S. C.; Moses, J.; Gamble, J. R.; Neto, C. Micropatterned Substrates Made by Polymer Bilayer Dewetting and Collagen Nanoscale Assembly Support Endothelial Cell Adhesion. Soft Matter 2012, 8, 9996-10007.

(15) Geoghegan, M.; Krausch, G. Wetting at Polymer Surfaces and Interfaces. Prog. Polym. Sci. 2003, 28, 261-302.

(16) Seemann, R.; Herminghaus, S.; Jacobs, K. Dewetting Patterns and Molecular Forces: A Reconciliation. Phys. Rev. Lett. 2001, 86, 5534-5537.

(17) Wensink, K. D. F.; Jérôme, B. Dewetting Induced by Density Fluctuations. Langmuir 2002, 18, 413-416.

(18) Suh, K. Y.; Lee, H. H. Dynamic Instability of Strongly Confined Thin Polymer Films in Spinodal Dewetting. Phys. Rev. Lett. 2001, 87, $1-4$.
(19) Raczkowska, J.; Montenegro, R.; Budkowski, A.; Landfester, K.; Bernasik, A.; Rysz, J.; Czuba, P. Structure Evolution in Layers of Polymer Blend Nanoparticles. Langmuir 2007, 23, 7235-7240.

(20) Raczkowska, J.; Bernasik, A.; Budkowski, A.; Sajewicz, K.; Penc, B.; Lekki, J.; Lekka, M.; Rysz, J.; Kowalski, K.; Czuba, P. Structures Formed in Spin-Cast Films of Polystyrene Blends with Poly (Butyl Methacrylate) Isomers. Macromolecules 2004, 7308-7315.

(21) Lee, S. H.; Yoo, P. J.; Kwon, S. J.; Lee, H. H. Solvent-Driven Dewetting and Rim Instability. J. Chem. Phys. 2004, 121, 4346-4351.

(22) Thiele, U.; Mertig, M.; Pompe, W. Dewetting of an Evaporating Thin Liquid Film: Heterogeneous Nucleation and Surface Instability. Phys. Rev. Lett. 1998, 80, 2869-2872.

(23) Brochard-Wyart, F.; Debregeas, G.; Fondecave, R.; Martin, P. Dewetting of Supported Viscoelastic Polymer Films: Birth of Rims. Macromolecules 1997, 30, 1211-1213.

(24) Bonaccurso, E.; Butt, H. J.; Franz, V.; Graf, K.; Kappl, M.; Loi, S.; Niesenhaus, B.; Chemnitz, S.; Böhm, M.; Petrova, B.; et al. Water Induced Dewetting of Ultrathin Polystyrene Films on Hydrophilic Surfaces. Langmuir 2002, 18, 8056-8061.

(25) Xu, L.; Shi, T.; An, L. Nonsolvent-Induced Dewetting of Thin Polymer Films. Langmuir 2007, 23, 9282-9286.

(26) Liu, D.; Wang, T. Instability of Hydrophobic and Viscoelastic Polymer Thin Films in Water at Room Temperature. J. Phys. Condens. Matter 2013, 25, 415101.

(27) Stetsyshyn, Y.; Raczkowska, J.; Lishchynskyi, O.; Awsiuk, K.; Zemla, J.; Dąbczyński, P.; Kostruba, A.; Harhay, K.; Ohar, H.; Orzechowska, B.; et al. Glass Transition in Temperature-Responsive Poly(Butyl Methacrylate) Grafted Polymer Brushes. Impact of Thickness and Temperature on Wetting, Morphology, and Cell Growth. J. Mater. Chem. B 2018, 6, 1613-1621.

(28) Awsiuk, K.; Stetsyshyn, Y.; Raczkowska, J.; Lishchynskyi, O.; Dabczyński, P.; Kostruba, A.; Ohar, H.; Shymborska, Y.; Nastyshyn, S.; Budkowski, A. Temperature-Controlled Orientation of Proteins on Temperature-Responsive Grafted Polymer Brushes: Poly(Butyl Methacrylate) vs Poly(Butyl Acrylate): Morphology, Wetting, and Protein Adsorption. Biomacromolecules 2019, 20, 2185-2197.

(29) Lord, M. S.; Foss, M.; Besenbacher, F. Influence of Nanoscale Surface Topography on Protein Adsorption and Cellular Response. Nano Today 2010, 5, 66-78.

(30) Owens, D. K.; Wendt, R. C. Estimation of the Surface Free Energy of Polymers. J. Appl. Polym. Sci. 1969, 13, 1741-1747.

(31) Raczkowska, J.; Bernasik, A.; Budkowski, A.; Rysz, J.; Kowalski, K.; Lekka, M.; Czuba, P.; Lekki, J. Pattern Replication Examined with Integral Geometry Approach: Application to Ion Milling of Polymer Blend Films. Thin Solid Films 2005, 476, 358-365.

(32) Raczkowska, J.; Rysz, J.; Budkowski, A.; Lekki, J.; Lekka, M.; Bernasik, A.; Kowalski, K.; Czuba, P. Surface Patterns in Solvent-Cast Polymer Blend Films Analyzed with an Integral-Geometry Approach. Macromolecules 2003, 36, 2419-2427.

(33) Zemla, J.; Gajos, K.; Awsiuk, K.; Rysz, J.; Budkowski, A. Sequential Binary Protein Patterning on Surface Domains of ThermoResponsive Polymer Blends Cast by Horizontal-Dipping. Mater. Sci. Eng. C 2019, 99, 1477-1484.

(34) Palasz, A. T.; Thundathil, J.; Verrall, R. E.; Mapletoft, R. J. The Effect of Macromolecular Supplementation on the Surface Tension of TCM-199 and the Utilization of Growth Factors by Bovine Oocytes and Embryos in Culture. Anim. Reprod. Sci. 2000, 58, 229-240.

(35) Edwards, S. A.; Williams, D. R. M. Surface Tension of Electrolyte Solutions: Comparing the Effects of Ionic Dispersion Forces and Solvation. Europhys. Lett. 2006, 74, 854-860.

(36) van Oss, C. The Properties of Water and Their Role in Colloidal and Biological Systems; Elsevier, 2008.

(37) Okur, H. I.; Chen, Y.; Wilkins, D. M.; Roke, S. The Jones-Ray Effect Reinterpreted: Surface Tension Minima of Low Ionic Strength Electrolyte Solutions Are Caused by Electric Field Induced WaterWater Correlations. Chem. Phys. Lett. 2017, 684, 433-442.

(38) Tripp, B. C.; Magda, J. J.; Andrade, J. D. Adsorption of Globular Proteins at the Air/Water Interface as Measured via Dynamic Surface Tension: Concentration Dependence, Mass-Trans- 
fer Considerations, and Adsorption Kinetics. J. Colloid Interface Sci. 1995, 173, 16-27.

(39) Nino, M. R. R.; Patino, J. M. R. Surface Tension of Protein and Insoluble Lipids at the Air-Aqueous Phase Interface. J. Am. Oil Chem. Soc. 1998, 75, 1233.

(40) Dalnoki-Veres, K. S.; Dutcher, J. R.; Forrest, J. A. Dynamics and Pattern Formation in Thin Polymer Films. Physic in Canada 2003.

(41) Reiter, G. Dewetting of Thin Polymer Films. Phys. Rev. Lett. 1992, 68, 75-78.

(42) Brochard Wyart, F.; Daillant, J. Drying of Solids Wetted by

Thin Liquid Films. Can. J. Phys. 1990, 68, 1084-1088.

(43) Reiter, G. Evolution of Rim Instabilities in the Dewetting of Slipping Thin Polymer Films. J. Adhes. 2005, 81, 381-395.

(44) Meredith, J. C.; Smith, A. P.; Karim, A.; Amis, E. J. Combinatorial Materials Science for Polymer Thin-Film Dewetting. Macromolecules 2000, 33, 9747-9756.

(45) Menissez, C.; Sixou, B.; David, L.; Vigier, G. Dielectric and Mechanical Relaxation Behavior in Poly(Butyl Methacrylate) Isomers. J. Non-Cryst. Solids 2005, 351, 595-603.

(46) Ferry, J. D. Viscoelastic Properties of Polymers; Wiley 1980.

(47) Reiter, G. Mobility of Polymers in Films Thinner than Their Unperturbed Size. EPL 1993, 23, 579-584.

(48) Tsui, O. K. C. Anomalous Dynamics of Polymer Films. In Polymer Thin Films; Tsui, O. K. C.; Russell, T. P.; World Scientific Singapore, 2008; 267-294.

(49) Raptis, I.; Diakoumakos, C. D. Non-Destructive Method for Monitoring Glass Transitions in Thin Photoresist Films. Microelectron. Eng. 2002, 61-62, 829-834.

(50) Tretinnikov, O. N. Wettability and Microstructure of Polymer Surfaces: Stereochemical and Conformational Aspects. J. Adhes. Sci. Technol. 1999, 13, 1085-1102.

(51) Isa, L.; Lucas, F.; Wepf, R.; Reimhult, E. Measuring SingleNanoparticle Wetting Properties by Freeze-Fracture Shadow-Casting Cryo-Scanning Electron Microscopy. Nat. Commun. 2011, 2, 1441.

(52) Milne, A. J. B.; Amirfazli, A. The Cassie Equation: How It Is Meant to Be Used. Adv. Colloid Interface Sci. 2012, 170, 48-55.

(53) Gajos, K.; Szafraniec, K.; Petrou, P.; Budkowski, A. Surface Density Dependent Orientation and Immunological Recognition of Antibody on Silicon: TOF-SIMS and Surface Analysis of Two Covalent Immobilization Methods. Appl. Surf. Sci. 2020, 518, 146269.

(54) Kim, Y.-P.; Hong, M.-Y.; Shon, H. K.; Moon, D. W.; Kim, H.S.; Lee, T. G. Quantitative ToF-SIMS Study of Surface-Immobilized Streptavidin. Appl. Surf. Sci. 2006, 252, 6801-6804.

(55) Gajos, K.; Budkowski, A.; Petrou, P.; Awsiuk, K.; Misiakos, K.; Raptis, I.; Kakabakos, S. Spatially Selective Biomolecules Immobilization on Silicon Nitride Waveguides through Contact Printing onto Plasma Treated Photolithographic Micropattern: Step-by-Step Analysis with TOF-SIMS Chemical Imaging. Appl. Surf. Sci. 2020, 506, 145002 .

(56) Awsiuk, K.; Bernasik, A.; Kitsara, M.; Budkowski, A.; Petrou, P.; Kakabakos, S.; Prauzner-Bechcicki, S.; Rysz, J.; Raptis, I. Spectroscopic and Microscopic Characterization of Biosensor Surfaces with Protein/Amino-Organosilane/Silicon Structure. Colloids Surfaces B Biointerfaces 2012, 90, 159-168.

(57) Zemļa, J.; Lekka, M.; Raczkowska, J.; Bernasik, A.; Rysz, J.; Budkowski, A. Selective Protein Adsorption on Polymer Patterns Formed by Self-Organization and Soft Lithography. Biomacromolecules 2009, 10, 2101-2109.

(58) Poncin-Epaillard, F.; Vrlinic, T.; Debarnot, D.; Mozetic, M.; Coudreuse, A.; Legeay, G.; El Moualij, B.; Zorzi, W. Surface Treatment of Polymeric Materials Controlling the Adhesion of Biomolecules. J. Funct. Biomater. 2012, 3, 528-543.

(59) Telford, A. M.; Thickett, S. C.; Neto, C. Functional Patterned Coatings by Thin Polymer Film Dewetting. J. Colloid Interface Sci. 2017, 507, 453-469.

(60) Yuan, C.; Ouyang, M.; Koberstein, J. T. Effects of Low-Energy End Groups on the Dewetting Dynamics of Poly(Styrene) Films on Poly(Methyl Methacrylate) Substrates. Macromolecules 1999, 32, 2329-2333. 